\title{
Classical case of late-infantile form of metachromatic leukodystrophy
}

Sir,

We would like to share a rare case of late-infantile form of metachromatic leukodystrophy (MLD) presenting in our institution.

The parents of a 3-year-old boy reported in the pediatric outpatient department and gave a history of progressive psychomotor regression, disturbance of gait, and quadriplegia in their son for the last 1 year. The patient was admitted for workup, and magnetic resonance imaging (MRI) brain was performed the next day. The MRI scan revealed confluent T2 and fluid-attenuated inversion recovery hyperintensities in the periventricular white matter and centrum semiovale with linear and dot-like hypointensities within it characteristic of the "tigroid" and "leopard skin" appearance of demyelination [Figure 1a and b].
The posterior limb of internal capsule and the corpus callosum (genu, body, and splenium) were also involved [Figures 2 and 3]. The diffusion-weighted images revealed restriction in the periventricular white matter and corpus callosum [Figure 4]. The peripheral $\mathrm{U}$ fibers were spared, and no noticeable enhancement was seen in postcontrast images. In combination; the clinical and imaging findings were suggestive of late-infantile form of MLD. The diagnosis was confirmed biochemically by the reduced arylsulfatase A levels in peripheral white blood cells and $24 \mathrm{~h}$ urine assay.

MLD is a form of lysosomal storage disorder with autosomal recessive inheritance which occurs due to deficiency of arylsulfatase A enzyme resulting in accumulation of sulfatides in the peripheral and central white matter. ${ }^{[1]}$ The prevalence of MLD is about 1 in 


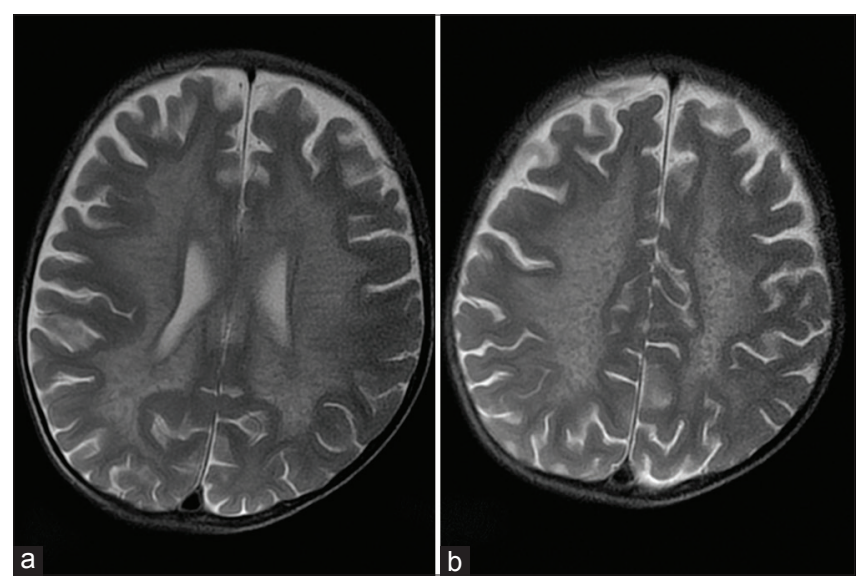

Figure 1: Magnetic resonance imaging axial T2-weighted images show the classical hypointense stripes and dots within the demyelinated white matter giving a "tigroid" appearance in the periventricular white matter (a) and the "leopard skin" appearance superiorly in the centrum semiovale (b)

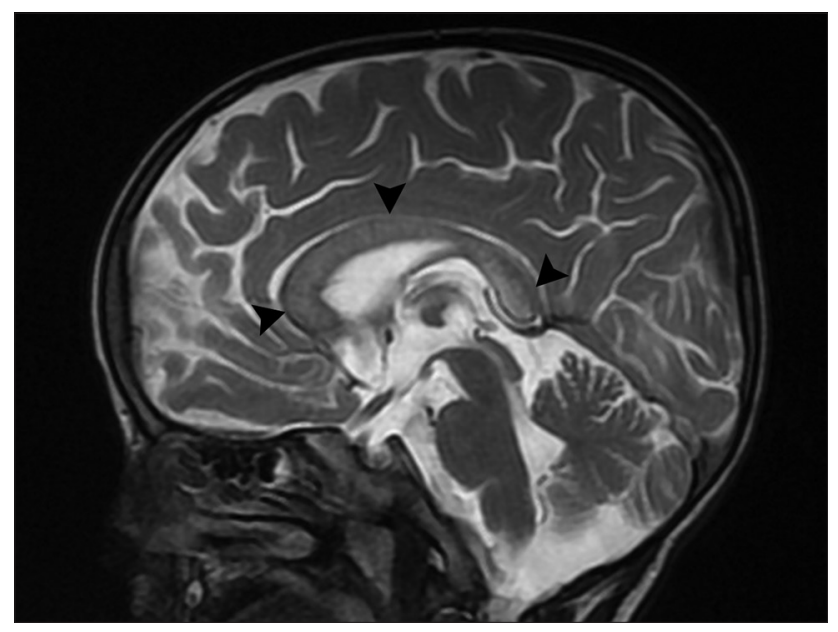

Figure 3: Midsagittal T2-weighted image shows the involvement of corpus callosum (arrowheads)

100,000 newborns ${ }^{[2]}$ and according to age, three forms have been described: Late-infantile, juvenile, and adult. Infantile form is the most common, manifesting at 1218 months of age with regression of motor development, intellectual decline and disturbances of speech/gait, and blindness. ${ }^{[1,2]}$ MRI findings of MLD include symmetric confluent hyperintense areas in periventricular white matter with a demonstration of "tigroid" or "leopard skin" pattern in deep white matter. ${ }^{[3]}$ The radially oriented hypointense stripes or dots which give the tigroid/leopard skin appearance have been related to relative sparing of myelin in the perivenular region. ${ }^{[4]}$ Diffusion-weighted MR imaging reveals restricted pattern of cytotoxic edema in the affected white matter in the absence of ischemia, the cause of which is probably due to restricted mobility of water molecules in the abnormal myelin..$^{[5]}$ Subcortical U-fiber sparing is characteristically seen in initial stage, but involvement may occur in later stages. ${ }^{[2]}$ There may also be variable

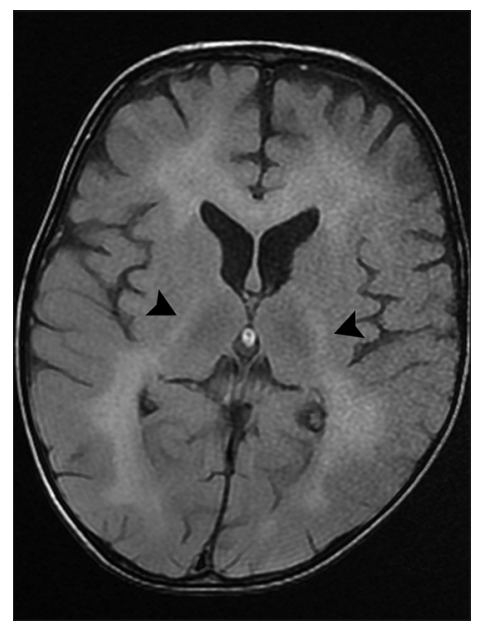

Figure 2: Axial T2-fluid attenuated inversion recovery image demonstrates a hyperintense signal in the posterior limb of internal capsule on both sides (arrowheads)

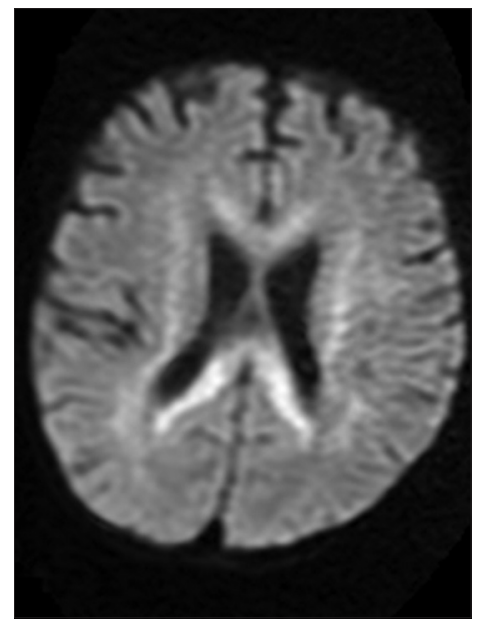

Figure 4: Axial diffusion-weighted image demonstrates restriction within the involved corpus callosum and periventricular white matter

involvement of corpus callosum, corticospinal tract, and cerebellar white matter. ${ }^{[1]}$ In postcontrast MR either no enhancement or punctate foci of enhancement can be seen in the background of nonenhanced demyelinated white matter. ${ }^{[1,2]}$

Apart from MLD, tigroid appearance can also occur in Pelizaeus-Merzbacher disease, but differentiation is usually possible based on the clinical context and low levels of arylsulfatase A in the peripheral white blood cells and urine in the former.

Prognosis in MLD is not good with progressive quadriplegia, decerebration, and death within 6 months to 4 years after onset. ${ }^{[1]}$

Our case is thus illustrative of the late-infantile form of MLD and showed typical clinical and MRimaging findings. 


\section{Financial support and sponsorship}

Nil.

\section{Conflicts of interest}

There are no conflicts of interest.

Narvir Singh Chauhan, Milap Sharma ${ }^{1}$, Amit Bhardwaj ${ }^{2}$

Departments of Radiodiagnosis, ${ }^{1}$ Paediatrics and ${ }^{2}$ Neurology, Dr. Rajendra Prasad Government Medical College, Tanda, Himachal Pradesh, India

Address for correspondence: Dr. Narvir Singh Chauhan,

Set No. D 6, Type V Residence, Dr. Rajendra Prasad Government Medical College Campus, Tanda, Kangra - 176 001, Himachal Pradesh, India. E-mail: narvirschauhan@yahoo.com

\section{References}

1. Cheon JE, Kim IO, Hwang YS, Kim KJ, Wang KC, Cho BK, et al. Leukodystrophy in children: A pictorial review of MR imaging features. Radiographics 2002;22:461-76.

2. Kim TS, Kim IO, Kim WS, Choi YS, Lee JY, Kim OW, et al. MR of childhood metachromatic leukodystrophy. AJNR Am J Neuroradiol 1997;18:733-8.
3. Faerber EN, Melvin J, Smergel EM. MRI appearances of metachromatic leukodystrophy. Pediatr Radiol 1999;29:669-72.

4. van der Voorn JP, Pouwels PJ, Kamphorst W, Powers JM, Lammens M, Barkhof F, et al. Histopathologic correlates of radial stripes on MR images in lysosomal storage disorders. AJNR Am J Neuroradiol 2005;26:442-6.

5. Sener RN. Metachromatic leukodystrophy: Diffusion MR imaging findings. AJNR Am J Neuroradiol 2002;23:1424-6.

This is an open access article distributed under the terms of the Creative Commons Attribution-NonCommercial-ShareAlike 3.0 License, which allows others to remix, tweak, and build upon the work non-commercially, as long as the author is credited and the new creations are licensed under the identical terms.

\begin{tabular}{|l|l|}
\hline \multicolumn{2}{|c|}{ Access this article online } \\
\hline Quick Response Code: & Website: \\
\hline & www.ruralneuropractice.com \\
\cline { 2 - 3 } & \\
\hline & \\
\hline
\end{tabular}

How to cite this article: Chauhan NS, Sharma M, Bhardwaj A. Classical case of late-infantile form of metachromatic leukodystrophy. J Neurosci Rural Pract 2016;7:473-5. 